\title{
JUSTIÇA CONSTITUCIONAL E DEMOCRACIA DE DIREITOS ${ }^{1}$
}

\section{CONSTITUTIONAL JUSTICE AND DEMOCRACY OF RIGHTS}

\author{
CARLOS BOLONHA ${ }^{2}$ \\ HENRIQUE RANGEL ${ }^{3}$ \\ BERNARDO ZETTEL ${ }^{4}$
}

\begin{abstract}
RESUMO: A falta de efetivação de direitos fundamentais tem se apresentado como um dos problemas centrais nos Estados Democráticos de Direito. Recentemente, o poder Judiciário se transformou, ao longo do mundo, em protagonista no desempenho deste papel. Os estudos sobre jurisdição constitucional, portanto, são insuficientes em responder e reverter este quadro. Restringir-se a uma perspectiva meramente jurídico-formal não é o bastante. Discutir efetivação de direitos exige, além da técnica normativa, uma atividade das instituições democráticas substancial. Deve-se reconhecer a relevância de um sistema de direitos acima de suas próprias competências. Para que o problema identificado possa ser combatido, no Brasil, é necessário analisar como esta matéria está imersa em uma relação entre direito e política; como o judicial review, após ganhar entornos políticos na Suprema Corte dos EUA, esclarece qual o papel das cortes constitucionais em um Estado Democrático de Direito; e a insuficiência do princípio majoritário ao lado da configuração de uma nova concepção de democracia: a democracia de direitos.
\end{abstract}

PALAVRAS-CHAVE: Justiça Constitucional; Eficácia de Direitos; Judicial Review; Suprema Corte dos EUA; Democracia de Direitos.

\footnotetext{
Artigo recebido em 18.03.2012. Pareceres emitidos em 10.05.2012 e 08.08.2012.

Artigo aceito para publicação em 13.08.2012.

${ }^{1}$ Este artigo foi elaborado no âmbito do Grupo de Pesquisa Teoria da Constituição e Teoria das Instituições (GP-TCTI) da Universidade Federal do Rio de Janeiro com financiamento do Conselho Nacional de Desenvolvimento Científico e Tecnológico (CNPq), pela concorrência do Edital Universal 14/2011 (Processo $n^{\circ}$ 480729/2011-5), e da Fundação Carlos Chagas Filho de Amparo à Pesquisa do Estado do Rio de Janeiro, pela concorrência do Edital no 9 de 2011 (Processo $n^{\circ}$ E-26/111.832/2011), além de Bolsa de Iniciação Científica (IC-FAPERJ) - solicitante Henrique Rangel em orientação de Carlos Bolonha.

${ }^{2}$ Professor Adjunto do Departamento de Direito do Estado e do Programa de Pós-Graduação em Direito da Universidade Federal do Rio de Janeiro.bolonhacarlos@gmail.com

${ }^{3}$ Graduando em Direito pela Universidade Federal do Rio de Janeiro. Bolsista em Iniciação Científica (IC-FAPERJ). henriquerangelc@gmail.com

${ }^{4}$ Graduando em Direito pela Universidade Federal do Rio de Janeiro. b_zettel@hotmail.com
} 


\begin{abstract}
The lack of efficacy on basic rights is presented as one of central problems in a democratic government. Recently, the Judiciary assumed, around the world, the role of protagonist in this matter. Studies about constitutional jurisdiction is, thus insufficiently in answer and revert this frame. A restricted legal and formal perspective is not enough. Discuss the efficacy of rights requires, more than normative technics, a substantial activity of democratic institutions. It is necessary to recognize the relevance of a system of rights, higher than the constitutional powers of the three branches. In Brazil, the combat of this problems must be analyzes by how this matter is immersed in a relation between law and politics, how judicial review, after gains political contours of U.S. Supreme Court, clarifies the role of constitutional courts in democratic governments, and the insufficiency of the majoritarian principle beside the configuration of a new conception of democracy: the democracy of rights.

KEYWORDS: Constitutional Justice; Efficacy of Rights; Judicial Review; U.S. Supreme Court; Democracy of Rights.
\end{abstract}

SUMÁRIO: Introdução; 1. Entre Jurisdição e Justiça Constitucionais; 2. A Teoria Constitucional dos EUA entre Direito e Política; 3. O Judicial Review com Entornos Políticos; 4. O Papel da Corte Constitucional e do Judicial Review; 5. A Democracia de Direitos; Conclusão; Referências Básicas.

SUMMARY: Introduction; 1. Between Constitutional Jurisdiction and Constitutional Justice; 2. The American Constitutionalism between Law and Politics; 3. Judicial Review with a Political Disposition; 4. The Role of Constitutional Court and Judicial Review; 5. The Democracy of Rights; Conclusion; Bibliography.

\title{
INTRODUÇÃO
}

A temática da justiça constitucional se apresenta como um dos temas centrais e mais complexos dos estudos da teoria do direito e do direito constitucional das últimas décadas, no plano internacional, e dos últimos anos, no plano nacional. O tema se configura como um instrumento indispensável à justiça dos homens e a persecução da consolidação e do desenvolvimento do Estado de Direito Democrático.

Por mais que pensadores e estudiosos descrevam ou discutam a crise do Direito, no presente momento, do ponto de vista da sua legalidade a de caráter jurídico-formal - ou da sua legitimidade - a de caráter políticosubstancial - há que se reconhecer, desde já, que a fundamentação da vida humana e a dos valores morais e sociais têm cada vez mais se revestido da proteção constitucional. Esta é uma condição idealizada para os cidadãos no Estado de Direito Democrático inquestionável. Nos dias de hoje, poucas constituições deixam de cuidar dos direitos fundamentais, logo, no seus primeiros títulos, a exemplo da Constituição da República Federativa do Brasil de 1988. Isto demonstra que a Constituição e a sua atividade jurisdicional continuam como um plano de efetivação dos direitos e garantias individuais de maneira a assegurar legitimamente, em última instância, a força normativa, as instituições, os processos judiciais e, sobretudo, a justiça, franqueada desde Platão e Aristóteles até Rawls e Habermas a um absolutismo incontornável. 
O estudo da jurisdição e da justiça constitucionais recebeu um enriquecimento teórico significativo com o desenvolvimento da ideia norteamericana de judicial review. O instituto, desde o seu surgimento, representa um importante canal para efetivação de direitos fundamentais e a experiência da Suprema Corte dos EUA é referência de uma Corte Constitucional de reconhecido papel democrático. Pode-se afirmar, ainda, que a contribuição de Stephen Griffin da teoria à prática jurisprudencial, em assuntos constitucionais, reforça a necessidade de repensar o sentido de democracia. Anteriormente, a teoria constitucional americana, ao discutir direitos fundamentais e sua efetivação, costumava fortalecer um debate em torno de direitos das minorias e dificuldade contra-majoritária. Segundo Griffin, uma nova forma de pensamento parece se construir. Identificando, com base em um princípio de proteção igualitária dos cidadãos, a dignidade pertencente a cada um dos indivíduos, o exercício das prerrogativas civis e políticas passam a compor um conceito distinto de democracia que supera a máxima majoritária: a democracia de direitos. A análise desta concepção da democracia e do judicial review é capaz de redesenhar todo o papel das instituições e, em particular, das Cortes Constitucionais; algo fundamental para o aprimoramento das técnicas de efetivação de direitos e de justiça constitucional.

\section{ENTRE JURISDIÇÃO E JUSTIÇA CONSTITUCIONAIS}

É preciso, em primeiro lugar, observar que não há que se identificar jurisdição constitucional à ideia instrumental do tema controle jurisdicional da constitucionalidade das leis, já que este representa o aspecto instrumental da função jurisdicional ${ }^{5}$. Em segundo lugar, há também que se fazer a observação de que a ideia de justiça constitucional se reveste de um caráter legitimatório próprio dos valores explícitos na esfera da razão pública de uma determinada sociedade; o que não necessariamente se apresenta sob a ótica técnica e formal da ideia de jurisdição constitucional ${ }^{6}$. É de fundamental

\footnotetext{
${ }^{5}$ Podemos buscar a origem do tema jurisdição constitucional entre os alemães com a ideia da Verfassungsgerichtsbarkeit.

${ }^{6}$ A ideia de razão pública tecida, pela primeira vez, em $A$ Theory of Justice, é revisitada por Rawls em seu trabalho publicado na University of Chicago Law Review, no ano de 1997, com o título de The Idea of Public Reason Revisited. Neste novo texto, Rawls pretende demonstrar como o conceito de razão pública, central para a construção de sua justiça como equidade é intrinsecamente conectado com uma das principais características da democracia moderna o pluralismo político: "The idea of publica reason, as I understand it, belongs to a conception of a well ordered constitutional democratic society. The former and content of this reason - the way it is understood by citizens and how it interprets their political relationship - is part of the idea of democracy itself. This is because a basic feature of democracy is the fact of reasonable pluralism - the fact that a plurality of conflicting reasonable comprehensive doctrines, religious, philosophical and moral, is the normal result of its culture of free institutions. Citizens realize that they cannot reach agreement or even approach mutual understanding on the basis of their irreconcilable comprehensive doctrines. In view of this, they need to consider what kinds of reasons they may reasonably give one another when fundamental political questions are at stake. I propose that in public reason comprehensive doctrines of truth or right be replaced by an idea of the political reason addressed to citizens as citizens" (RAWLS, 1997: 765-766).
} 
importância compreender a distinção teórica, mesmo que muito sutil, entre jurisdição e justiça constitucionais. A primeira possui um caráter jurídico-formal mais explicitado e coerente com a própria norma constitucional, ou seja, com o próprio elenco de direitos constitucionalizados, enquanto a segunda se consubstancia naqueles valores legitimatórios, sempre em transformação da sociedade constitucionalizada.

Não há que se duvidar, contudo, que a Constituição, como descreve Paulo Bonavides "é cada vez mais, num consenso que se vai cristalizando, a morada da justiça, da liberdade, dos poderes legítimos, o paço dos direitos fundamentais (...)" (BONAVIDES, 2004: 127). Na verdade, o que se deseja explicitar é a noção de justiça constitucional, no plano material e substancial, como sendo a realização da confluência e integração entre Constituição e direitos efetivados no plano sócio-político, ou seja, como se procede uma legitimação efetiva e racional, ou mesmo procedimental; diferente da noção de jurisdição constitucional que resulta de uma complexa função de garantir a Constituição por meio de sua própria competência, mesmo que na defesa dos direitos e liberdades fundamentais e na condução da segurança do ordenamento jurídico e da vida democrática. Deve-se perguntar, pois, se a jurisdição constitucional, na sua inequívoca necessidade de exercício, atinge, por meio do seu processo constitucional, a plena efetividade dos direitos que estão ali assegurados. De uma maneira não distinta desta hipótese, sustenta o jurista Vieira de Andrade:

Assim, os preceitos relativos aos direitos, liberdades e garantias são tipicamente e em regra, preceitos diretamente aplicáveis, que podem e devem ser objeto de uma concretização ao nível constitucional e portanto, é acessível à jurisprudência do Tribunal Constitucional. Diferentemente, a concretização jurídico-política é típica (embora só típica) dos preceitos relativos aos direitos sociais, remetendo a Constituição, em regra, para opções políticas que, por natureza, são próprias do legislador: tratando-se de questões em que estão em causa uma sensibilidade e uma legitimidade políticas, a concretização dos preceitos há de pertencer em primeira linha ao legislador devendo o Tribunal Constitucional, por princípio, respeitar o poder da maioria, desde que esta não ultrapasse os limites constitucionais (VIEIRA DE ANDRADE, 1995: 80).

O trecho acima apresenta uma preocupação que também pode ser encontrada na obra de Joaquim José Gomes Canotilho. Defende-se que a atuação da Constituição na realidade político-social, em uma dimensão formal, depende, em primeiro plano, da atuação do legislador infra-constitucional (CANOTILHO, 2001). Esta ideia é abordada por Canotilho ao tratar dos aspectos referentes à Constituição dirigente, com suas normas diretrizes, ante o grau de vinculação do legislador. O autor busca um diálogo harmônico entre a normatividade axiológica constitucional e os limites da discricionariedade política do legislador na conformação dos preceitos constitucionais expressos 
prima facie como metas a serem atingidas pela própria ordem democrática de Estado. Além da tese do jurista português, é possível acrescentar uma questão relevante em matéria de efetivação de normas constitucionais. Pode-se afirmar que a atividade legislativa corresponde a uma construção no plano da normatividade. Esta atividade precisa ser associada a um plano de faticidade, em que as instituições como um todo estejam desempenhando devidamente seus respectivos papéis em um Estado Democrático de Direito.

Há que se construir, assim, uma compreensão sobre, de um lado, a legitimidade da jurisdição constitucional, que está necessariamente atrelada ao teor legal ou formal da própria racionalidade jurídica constitucionalizada e, por outro lado, a legitimidade no exercício ou da aplicação da própria justiça constitucional. Será a possível e a cobiçada confluência entre estes pólos, o da legalidade e o da legitimidade, que se configura o paradigma epistemológico para o reconhecimento da jurisdição constitucional como um elemento propulsor da real e verdadeira democracia contemporânea. ${ }^{7} \mathrm{~A}$ equação que se deseja analisar é como a Constituição pode legitimar as ações políticas do Estado Democrático e, ao mesmo tempo, evitar que as instituições ou órgãos legitimados possam ameaçar o conteúdo legítimo sobre o qual ela mesma se fundamenta, como, numa visão filosófica, pondera Menelick de Carvalho Netto:

Por isso mesmo a oposição entre a constituição formal tomada como constituição ideal e a efetiva pragmática político-jurídica vista como constituição real é, ela própria, uma construção idealizada, uma armadilha conceitual que eterniza o que pretendera denunciar, pois, por um lado, é incapaz de revelar a natureza de idealidade normativa das terríveis pretensões idealizantes que ganham curso sob a capa do que denomina "realidade", e, por outro, absolutiza o poder de regulamentação de condutas da Constituição e do Direito em Geral (CARVALHO NETTO, 2004: 26).

E por que discutir a legitimidade, nos dois aspectos já delineados, o da jurisdição constitucional e na efetivação desta? Nos dias atuais, um Estado pautado pela estria democrática só será reconhecido como tal e conferirá legitimidade às suas instituições quando o seu regime político fundamentar e defender o binômio da soberania popular e da defesa dos direitos fundamentais

\footnotetext{
${ }^{7} \mathrm{Na}$ perspective habermasiana, a legitimidade do Direito somente é compatível com uma ordem legal coercitiva que não destrói os motivos racionais que sustentaram a sua criação. A Constituição, como um sistema de direitos, está submetida ao imperativo de conformar a autonomia política de cada membro da sociedade com os objetivos políticos que são traçados no processo de deliberação democrática. Dessa forma, o círculo da legitimidade constitucional é constantemente renovado com os valores que são decididos em procedimentos deliberativos de construção da opinião e da vontade políticas: "The key idea is that the principle of democracy derives from the interpenetration of the discourse principle and the legal form. I understand this interpenetration as a logical genesis of rights, which one can reconstruct in a stepwise fashion. One begins by applying the discourse principle to the general right to liberties - a right constitutive for the legal form as such - and ends by legally institutionalizing the conditions for a discursive exercise of political autonomy" (HABERMAS, 1996: 119).
} 
da pessoa humana de modo incontestável ${ }^{8}$. Resta apontar, pois, quem será o verdadeiro Gardien des Promesses, ou mesmo, num plano institucionalizado, que poder será responsável por tais exigências norteadoras de um constitucionalismo revigorado e mais humano? ${ }^{9}$ Não será outro senão o Poder Judiciário, por meio de seus órgãos ou por um Tribunal Constitucional específico que responderá, de maneira independente, à responsabilidade de garantir a Lei Fundamental e buscar, em última instância, o exercício permanente da justiça constitucional ${ }^{10}$.

\section{A TEORIA CONSTITUCIONAL DOS EUA ENTRE DIREITO E POLÍTICA}

Pode-se identificar uma visão de interpretação constitucional difundida por Stephen Griffin relativa ao judicial review norte-americano, em especial, na área de proteção igualitária (GRIFFIN, 2002). Compreende-se que não se deve apenas contar com a Suprema Corte no que tange à proteção dos direitos contra a discriminação assegurada pela Equal Protection Clause da Constituição norte-americana ${ }^{11}$. A pergunta, antes de mais nada, repousa no entendimento sobre a supremacia judicial e como esta pode ser justificável em uma democracia que assegura direitos individuais ${ }^{12}$. A ideia é a de que 0

\footnotetext{
${ }^{8}$ E são estes os institutos essenciais para "alargar" os horizontes da tradição do constitucionalismo moderno, apresentado por Ferdinand Lassalle e transformado e desenvolvido por tantos outros constitucionalistas contemporâneos (LASSALLE, 1988). O binômio mencionado é encontrado, ainda, com significativa relevância na obra de Habermas. Segundo este autor, ambos seriam fundamentos de modelos normativos de democracia e, na verdade, deveriam ser concebidos por uma relação de pressuposição mútua. Tal articulação seria, pois, a fundamentação de uma teoria procedimentalista, pois aproxima conceitos como Rule of Law e Demoracia (HABERMAS, 1996).

${ }_{9}$ O termo Gardien des Promesses encontra-se em (GARAPON, 1996). Neste livro, Garapon sustenta a desconstrução do poder institucionalizado e constrói a ideia do poder ético e justo a partir da figura central do juiz na sua atividade jurisdicional.

${ }_{10}$ Fábio Konder Comparato evidencia o Poder Judiciário como sendo o regulador eficaz do "espírito democrático". Mas atenta também para a importância do princípio fundamental da república democrática como sendo "a necessária correlação existente entre poder e responsabilidade". E mais: "a democracia é o regime político no qual ninguém, nem mesmo o povo soberano, exerce um poder absoluto, sem controles. O poder soberano do povo só pode ser exercido, legitimamente, no quadro da Constituição" E é de responsabilidade do Poder Judiciário avaliar os limites constitucionais da soberania popular e dos direitos fundamentais. Em sintonia com este princípio legitimatório, se alinha o jurista e ministro do Supremo Tribunal Federal, Gilmar Ferreira Mendes, que, em recente entrevista à Primeira Leitura de 11/2005, declara: "No Estado de Direito, não há soberano. Ninguém pode exercer suas atribuições de forma ilimitada, nem mesmo o STF". (COMPARATO, 2004).

${ }^{11}$ A Equal Protection Clause se encontra na Fourteenth Amendment da Constituição dos EUA, extraída dos seguintes termos: "AMENDMENT XIV, Section 1. All persons born or naturalized in the United States, and subject to the jurisdiction thereof, are citizens of the United States and of the State wherein they reside. No State shall make or enforce any law which shall abridge the privileges or immunities of citizens of the United States; nor shall any State deprive any person of life, liberty, or property, without due process of law; nor deny to any person within its jurisdiction the equal protection of the laws" (grifo nosso).

${ }^{12}$ Esta ideia está muito presente na teoria de Ronald Dworkin, para quem a garantia dos direitos individuais é a função mais importante do sistema jurídico. O direito não seria mais do que um dispositivo que tem como finalidade garantir os direitos dos indivíduos frente às agressões da maioria e do governo (DWORKIN, 1977).
} 
scrutiny - padrão de julgamento - não seria mais necessário para a jurisprudência de proteção igualitária ${ }^{13}$.

$\mathrm{Na}$ verdade, o problema das minorias nos Estados Unidos sempre foi, pelo menos nos últimos 40 anos, uma questão que traz em sua essência enormes discussões, uma vez que a Suprema Corte nunca se pautou por uma uniformidade nas suas decisões. A questão central, pois, se estabelece na percepção de que a Suprema Corte procura destruir direitos civis valiosos e a partir desta constatação, ao mesmo tempo, se impõe uma crítica de reflexão democrática ao judicial review, não somente no seu aspecto contramajoritário, mas, antes, que não está respeitando direitos individuais. E o mais preocupante é que este fenômeno está se sedimentando na estrutura institucional do Estado norte-americano e marcando consideravelmente a ordem constitucional dos Estados Unidos.

É de fundamental importância imaginarmos, como afirma Griffin, que se poderia encontrar uma democracia de direitos se, normativamente, pudéssemos afastar o sistema de padrões de julgamento (scrutiny) do judicial review. O conceito de democracia de direitos conecta necessariamente direitos com deliberação democrática. Ora, em um sistema democrático, os atores institucionais deveriam ter sempre como objetivo presente o desejo de criar, assegurar e promover os direitos constitucionais individuais. Ou seja, a ação governamental, seja pelos atores políticos, como o Legislativo (Congresso), seja pelos atores jurídicos, como o Judiciário (Suprema Corte), deveria procurar sempre manter e estender um sistema de direitos por intermédio de mecanismos estritamente democráticos.

O constitucionalismo norte-americano pode ser compreendido de imediato como uma mistura entre política e direito. A Constituição norte-americana serve, sem dúvida, como um enquadramento para a ação do governo e o estabelecimento de políticas públicas. No contexto da adjudicação pela Suprema Corte, percebe-se claramente a importância de suas decisões constitucionais para a delimitação de políticas de governo, tendo impacto direto nas políticas do governo federal e estadual. Tradicionalmente, a Suprema Corte se manifesta sobre assuntos constitucionais de caráter geral e abstrato. Os julgamentos estão, na maioria das vezes, voltados para as cláusulas presentes nas emendas constitucionais do Bill of Rights e da Civil War, causando sempre desafios grandiosos para os Justices:

Constitutional clauses that use terms drawn from political and moral ideals seem to lack some of the characteristics of ordinary legal rules. They do not provide the same guidance given by ordinary legal rules, thus creating tensions with the values embodied in the rule of law.

\footnotetext{
${ }^{13}$ Os scrutinies são padrões de julgamento - standards - que as Cortes Federais norte-americanas, dentro da cláusula de proteção igualitária, utilizam para acessar a constitucionalidade de classificações governamentais baseadas em raça e baseadas naquelas que infringem os direitos constitucionais fundamentais. (HALL, 1998: 845).
} 
The abstract character of these clauses means that it is difficult to tell when judges are following or deviating from the rules contained within them. Even if these clauses provide some direction, their practical effects is to delegate an unusual amount of power to judges (GRIFFIN, 1996: 127).

É curioso também notar que, dentro do sistema da common law, nem sempre existe um remédio por meio da adjudicação constitucional quando um direito é violado. O que gera sempre tensões. Por um lado, deve ser evitada qualquer tensão entre Constituição e outras formas de direito. Isto significa dizer que as decisões da Suprema Corte devem ser em números reduzidos para evitar maiores distúrbios no sistema político daquele país. De fato, devem ser encontrados métodos de interpretação sobre as cláusulas para que arranjos tradicionais no patamar político e na esfera jurídica não sofram grandes impactos. Por outro lado, a Suprema Corte deve ter influência necessária para estabelecer limites constitucionais para os agentes institucionais em nível federal e estadual. De acordo com os seus limites constitucionais, a Suprema Corte deve assegurar para cada cidadão os ideais de liberdade e de igualdade e estabelecer condições para que tais cláusulas e seus direitos possam ser efetivamente implementados.

Uma das características mais importantes da Suprema Corte é o fato de os Justices trabalharem separadamente para alcançar suas decisões. As ações coletivas a partir de deliberações são muito raras. Com frequência não se obtém maioria nas decisões e, sem dúvida, ocorrem incoerências. A legitimidade da Corte sempre está em questionamento uma vez que não há votação para as decisões. O processo de decisões envolve uma rede complexa de questões políticas com significativas consequências no âmbito político e legal da sociedade norte-americana. A Corte se vê constantemente no desafio de possuir discrição, estabilidade e certeza nas decisões de acordo com o Rule of Law.

A Constituição norte-americana, como o próprio documento esclarece, fundamenta o caráter da suprema lei. Mas, evidentemente, o constitucionalismo norte-americano está baseado na analogia entre Constituição e leis ordinárias de maneira que todos os indivíduos tenham os direitos e os deveres assegurados pelo Rule of Law. A Constituição é, da mesma forma, a "moldura" do governo federal permitindo a "feitura" da política nacional como um todo. Deve-se observar, de imediato, que a Constituição não é uma lei comum. Por sua natureza específica da generalidade e da abstração, no caso norte-americano, não é possível o controle restrito de sua aplicação, ou seja, não existem mecanismos institucionais para exigir a obrigatoriedade do cumprimento constitucional quando um ramo do governo, por exemplo, viola a Constituição. Os mecanismos controladores não são os mesmos que os aplicados a um indivíduo que viola uma lei ordinária. A Constituição não tem uma polícia específica para defender sua eficácia. Pelo fato de a Constituição ser o enquadramento das políticas públicas, das ações do governo, e não ter 
um controle específico para sua eficácia, ela está sempre sob pressão dos atores políticos em vista de usarem-na para benefícios específicos. E por isso, encontram-se tantas contradições nas esferas políticas e judiciárias da sociedade norte-americana. O judiciário, na verdade, em especial, a Suprema Corte, exerce o papel de intérprete, controlador e revisor da Constituição e de sua eficácia na sociedade democrática.

\section{O JUDICIAL REVIEW COM ENTORNOS POLÍTICOS}

Durante as últimas três décadas do século $\mathrm{XIX}$ e as primeiras três décadas do século $X X$, a discussão e a valorização do judicial review se tornaram realmente marcantes. O Estado deveria ser provocador e cerceador dos novos problemas político-institucionais que se apresentavam naquele período histórico de profundas transformações na sociedade norte-americana - da Guerra Civil à Grande Depressão. As emendas resultantes do período da Guerra Civil deram enorme oportunidade à Suprema Corte para exercer revisões sobre as atividades dos governos federal e estaduais. Foi com o New Deal, nos anos 30, que se firmou por definitivo a prática permanente de uma Corte ativa e determinada a participar das transformações políticoconstitucionais de uma sociedade em evolução. Qual era, então, o papel desta Corte no sistema político? Esta Corte foi, na verdade, capaz de apontar a inconstitucionalidade de leis federais de taxação, de limitar leis antitrustes, de restringir o crescimento de sindicatos. Algumas das decisões foram bastante conservadoras, mas outras foram de grande importância para as reformas sócio-econômicas. Foram tais decisões que provocaram o início do debate sobre o judicial review como um instrumento de real regulação dentro do sistema constitucional e político dos EUA. Este período, conhecido como a Era Lochner, marca um momento de profunda prolixidade e contradições dentro da Suprema Corte quando não se sabia exatamente sob que influência ideológica aquela se encontrava ${ }^{14}$. Muito se discute sobre este período da Suprema Corte no que diz respeito a seu apoio a padrões verdadeiramente democráticos ${ }^{15}$. A aspiração política de democracia, nos parâmetros que conhecemos hoje, não existia em profusão na Era Lochner: os afro-americanos, os pobres e as mulheres, entre outros, eram suprimidos pela força e pela fraude de decisões em nível federal de maneira muito pouco democrática e pouco se falava em direitos civis.

É muito importante considerar este período para a análise do judicial review porque neste momento a crítica repousava em este método ser totalmente anti-democrático uma vez que nos EUA não estava estabelecida uma democracia plena e majoritária: havia, contrariamente, uma democracia constitucional ou representativa dos interesses particulares. Na verdade, os EUA e a democracia evoluíram conjuntamente. A democracia, nada mais é do

\footnotetext{
${ }^{14}$ Lochner v. New York, 198 U.S. 45 (1905).

15 Esta é uma ideia especialmente discutida por alguns historiadores e constitucionalistas norte-americanos como Griffin (GRIFFIN, 1996: 102).
} 
que um processo crítico e participativo sobre as transformações sócio-políticoeconômicas de determinado período histórico. Foi, pois, neste momento que o sufrágio universal foi conquistado. Hoje, por conseguinte, a democracia norte-americana reconhece a importância da garantia dos direitos civis e das liberdades civis. Não existem restrições baseadas em sexo, classe, raça para o direito de votar, por exemplo. A democracia aceita também, da mesma maneira, no presente momento, partidos representativos de grupos para sua participação política.

No ano de 1937, se estabelece a grande crise entre o poder executivo, com a figura do presidente Roosevelt, e o poder Judiciário, representado pela Suprema Corte, no que se refere a decisões contrárias ao New Deal. Roosevelt consegue, após sucessivas derrotas, o apoio da Corte em favor do New Deal. A Corte tinha tido uma participação decisiva, por meio do judicial review, no controle do governo em regular a economia em moldes intervencionistas. O New Deal mostrou, assim, que havia uma clara tensão entre o exercício do judicial review e o governo democrático estabelecido. A Corte, a partir deste momento, resolve que sua função de rever legislações não era somente o seu papel constitucional: seu novo rumo era defender direitos individuais, especialmente, aqueles relacionados com o processo político como a proteção da Primeira Emenda sobre liberdade de expressão ${ }^{16}$. O judicial review torna-se, deste modo, uma justificativa para o exercício pleno dos direitos individuais por minorias a partir de um processo democrático, como nos lembra Gargarella:

La argumentación presentada por Hamilton - y luego retomada por el juez Marshall em el famoso caso "Marbury v. Madison" - pasó a constituirse, desde entonces, en uma de las más sólidas y difundidas defensas del control judicial. Em cualquier país que acepta la revisión judicial de las leyes, se recurre a dichos similares a los de Hamilton: porque se pretende el "autogobierno" del pueblo, porque se pretende mantener inviolada la autoridad del pueblo - enraizada en la constitución - es que se requiere un órgano capacitado para revisar la validez de las leyes (GARGARELLA, 1997: 57).

A Corte passava então, com o espírito descrito acima, a ter um papel legítimo na defesa do Bill of Rights contra incursões majoritárias ${ }^{17}$.

\footnotetext{
${ }^{16}$ Em relação a este tópico, sugerimos o debate apresentado por Ronald Dworkin em (DWORKIN, 2000).

${ }^{17}$ Foi a partir da famosa nota de rodapé $\mathrm{n}^{\circ} 4$ de Carolene Products que a Corte revelou uma grande consciência sobre a segurança dos direitos constitucionais quando a legislação infringe o texto constitucional, tem efeitos que excluem indivíduos do processo político e é resultado de discriminação contra minorias. United States v. Carolene Products Co., 304 U.S. 144, 152-53 no 4 (1938). Havia também uma previsão de que a Corte tomaria medidas cabíveis para quando o processo democrático fosse interrompido, mesmo quando não houvesse previsão constitucional para tanto.
} 
Houve, naturalmente, um profundo debate sobre a abolição ou a restrição do judicial review, como observa Bickel, entre outros ${ }^{18}$. A preocupação era determinar a especificidade do papel e da função da Suprema Corte na democracia norte-americana, como atenta Griffin:

The thought that guided such scholarly efforts was that the undemocratic character of judicial review meant that the Court had to behave in a certain way to avoid repeating the mistakes of the pré-New Deal Court. Thus the debate is better characterized as one over the proper role of the Supreme Court in American democracy (GRIFFIN, 1996: 106).

\section{O PAPEL DA CORTE CONSTITUCIONAL E DO JUDICIAL REVIEW}

Existem dois importantes momentos que marcam certa descontinuidade no constitucionalismo norte-americano. Os Estados Unidos não foram sempre uma democracia de direitos. O primeiro momento que marca um novo rumo para esta tradição foi o movimento pelos direitos civis, o que mudou profundamente o comportamento do próprio governo à época. Da mesma forma, ao se chamar a atenção para os direitos civis, tornando-os parte do sistema político, houve, concorrencialmente o processo de politização do próprio direito. Tais fenômenos provocaram o debate sobre a supremacia judicial, de forma a melhor compreendermos a politização dos direitos em todos os poderes, inclusive na Suprema Corte.

Politizar direitos significou, pois, a manifestação de todos os atores governamentais em função de uma proteção dos direitos constitucionais e legais. Richard Kay esclarece:

Constitutionalism is risk-averse in the sense that it prefers the awkwardness of rigidly bound state action to the possibility that government will overshoot the mark in dealing with new circumstances and thus needlessly restrict private action. That may, in fact, be an especially worrisome hazard in a democratic regime where a government will be vulnerable to the appeal of short-term considerations of collective welfare at the expense of the liberties of individuals and minorities (KAY, 1999: 24).

Não existem dúvidas de que a Suprema Corte continua em sua trajetória de proteger direitos constitucionais ${ }^{19}$. Cass Sustein apresenta alguns princípios básicos que fundamentam a constituição, a saber: proteção contra prisão nãoautorizada, proteção para discordância política, o direito ao voto, a liberdade religiosa e a proteção contra discriminação racial e sexual (SUSTEIN, 1999). $\mathrm{Na}$ verdade, não só a Constituição e Suprema Corte estão prontas para defender tais direitos, mas também os poderes políticos também o fazem de uma forma ou de outra. O Congresso norte-americano apresenta inúmeros

\footnotetext{
${ }^{18}$ Pode-se analisar, ainda (ELY, 2001).

19 Chamamos a atenção para a recente decisão da Corte Suprema sobre o caso Michigan. Para melhor informação recomenda-se (DWORKIN, 2003-2004).
} 
casos em que participou efetivamente na defesa dos direitos constitucionais e legais, entre eles o Equal Pay Act (1963) e o Civil Rights Act (1964), como exemplos sólidos desta participação reguladora e controladora. O Congresso norte-americano tem tido ainda grande participação na garantia Equal Protection Clause da Fourteenth Amendment. Se analisarmos comparativamente as ações do Congresso e da Suprema Corte, poderemos verificar que muitas vezes o Congresso tem sido mais efetivo e confiável na defesa de direito civis em resposta a decisões da Suprema Corte que, por muitas vezes, restringiram os direitos contra a discriminação. Um exemplo disto foi quando a Suprema Corte restringiu a abrangência de diversas leis anti-discriminação em Grove City College v. Bell, o Congresso, imediatamente, votou a Lei de Restauração dos Direitos Civis (1987) ${ }^{20}$. E assim foram em muitos outros casos. ${ }^{21} \mathrm{O}$ importante é que seja identificada a ideia de que todos os atores políticos na democracia norte-americana trabalham em favor dos direitos, criando, promovendo e executando direitos constitucionais importantes. A Suprema Corte, em não raras ocasiões, tem deixado a desejar no que se refere à proteção de importantes direitos constitucionais, a saber: City of Mobile (lei dos direitos de voto) e Grove City College (discriminação racial e sexual), como bem analisa Cornell Clayton:

Much attention has focused on how electoral dealignment impacts Congress and the presidency (Cox and Kernell 1991; Thurber 1991). Less well understood, but equally important, is it impact on the judiciary. Initially, dealignment led to a new judicial politics that made the Court both a more regular and a more independent source of policy innovation. (...) The twin developments of electoral dealignment and a collapse in consensual jurisprudence explain much about the role and decision making of the Rehnquist Court. To begin with, rather than defining moments in the relationship between the Court and the elected branches, appointments of justices during the late -1980s and 1990s have increasingly become defining moments for the relationship between Congress and the president. As such they become exercises in pragmatism and conflict avoidance (CLAYTON, 1999: 155-157).

\section{A DEMOCRACIA DE DIREITOS}

A ideia de democracia de direitos é substancialmente fundada na noção de cidadania que consiste em uma garantia efetiva de parâmetro nacional de direitos civis, incluindo aí o direito ao voto. Hoje, sustenta-se o repúdio a qualquer restrição ou discriminação à propriedade, classe, raça, sexo no exercício de qualquer direito civil. Entende-se, ainda, a necessidade de se aceitar uma forma populista de democracia em que todos os poderes eleitos são entendidos como eleitos diretamente pelo povo.

\footnotetext{
${ }^{20}$ Grove City College v. Bell, 465 U.S. 555 (1984).

${ }^{21} \mathrm{O}$ trabalho de Griffin enumera exaustivamente os casos em que o Congresso responde à Suprema Corte (GRIFFIN, 2002).
} 
Diferentemente dos Fundadores, há dois séculos, ou dos Progressistas, no início do século passado, na sociedade norte-americana de hoje, é aceito um tipo de estrutura em que se pauta pelo pluralismo racial e étnico. O marco histórico para o surgimento desta democracia de direitos é o movimento pelos direitos civis nos anos 50 e 60, em que surge uma nova compreensão sobre a ideia de cidadania, quando levou ao fim da segregação racial, por exemplo ${ }^{22}$. A lógica constitucional de poderes separados começou a funcionar na defesa da política de direitos civis. A Suprema Corte era convocada a participar deste processo por aclamação popular e se falhasse no seu papel de defensora dos ideais constitucionais, os cidadãos poderiam recorrer aos poderes eleitos, tais como o Congresso:

Furthermore, Charles Epp's valuable study of the "support-structure" of the rights revolution makes clear that Court decisions that are part of the civil rights movement were themselves the product of a democratization of access to the federal judiciary. That is, the Court did not simply act on its own to protect individual rights against majoritarian attack. It acted with the support of groups of citizens who summoned significant resources in a quest to protect rights. Exercising their democratic rights to organize to the extent possible, these citizens provided a crucial impetus for Court decisions that defended the rights of the individual (GRIFFIN, 2002: 292).

Houve, naturalmente, retrocessos, como na Era Nixon, quando figuras conservadoras invadiram a Suprema Corte, estabelecendo novos rumos para

\footnotetext{
${ }^{22}$ O Movimento pelos Direitos Civis nos Estados Unidos despontou durante os anos de 1950 e 1960, em função dos novos debates travados na sociedade civil norte-americana acerca dos direitos das minorias. Pode-se dizer que a II Guerra Mundial provocou um redimensionamento estrutural das classes sociais nos Estados Unidos, fenômeno que foi acompanhado, sobretudo, pela atuação pioneira da Suprema Corte na defesa dos direitos civis. Nesse sentido, destaca Michael Klarman: "World War II's impact on judicial civil rights rulings was dramatic. In 1944 Smith v. Allwright invalidated the Texas Democratic Party's exclusion of blacks, overruling by an eight-to-one vote a unanimous decision from just nine years earlier-an unprecedented turnabout in American constitutional history. In 1948 Shelley v. Kraemer barred judicial enforcement of racially restrictive covenants, rejecting dicta from a unanimous Court ruling of 1926 and departing from the result reached by nearly 20 state supreme courts. Most famously, in 1954 Brown v. Board of Education invalidated public school segregation, rejecting nearly three-quarters of a century's worth of precedent and plainly departing from the original understanding of the Fourteenth Amendment. Meanwhile, Congress still remained unable to pass a single civil rights bill. Every two years in the 1940s, the House passed anti-poll-tax bills, which failed in the Senate. In 1950 fair employment practices legislation also failed to survive Senate filibuster. In the 1950s Congress neither endorsed Brown nor passed proposed enforcement measures, such as empowering the Attorney General to bring school desegregation suits or cutting off federal education funds to institutions practicing racial segregation. Finally, in 1957, Congress passed its first civil rights law in 82 years, but it was limited to voting rights, and failed to adequately protect even them" (KLARMAN, 2002). Smith v. Allwright, 321 U.S. 649 (1944); Shelley v. Kraemer, 334 U.S. 1 (1948); Brown v. Board of Education (I), 347 U.S. 483 (1954); e Brown v. Board of Education (II), 349 U.S. 294 (1955).
} 
as decisões de cunho democratizante no que tange aos direitos civis $^{23}$. No governo Reagan, novamente a Corte sofre de compromissos políticos para patrocinar a administração do governo a aplicar medidas ideológicas consistentes. Aqui, observa-se um processo de politização da nomeação para a Suprema Corte mais forte do que nunca. Na verdade, os políticos norteamericanos já haviam percebido que, desde a Corte de Warren, a Corte como instituição forte poderia sempre afetar seus objetivos na agenda política. E por esta razão a Corte não seria, a partir da era Reagan, uma instituição com independência política para assegurar a proteção dos direitos civis:

The contemporary Court has thus become another forum in which political battles over individual rights are played out. It is closely balanced between the contending sides and each presidential election and possible vacancy is monitored for its potential impact on constitutional issues. Indeed, the politization of the appointment process makes it unlikely that the Court can perform a special function in educating the citizenry or assuming a vanguard role to promote a national dialogue on rights (GRIFFIN, 2002: 295.).

A democracia de direitos procura, pois, ante o debate sobre a legitimidade do judicial review, descobrir que poder ou nível do governo é mais eficiente na criação e na execução de direitos: o Legislativo ou o Judiciário. Um dos grandes problemas da crítica contra-majoritária à revisão judicial era mostrar que esta nunca se preocupou com a democracia como sendo um valor intrínseco ao processo de revisão. Muitos teóricos como Amy Gutmann e Robert Dahl, entre outros, mostram que o que importa sobre democracia não é simplesmente a regra de maioria, mas o compromisso de tratar cidadãos de maneira igualitária e assegurar que o governo trabalhe em favor de todos de modo uniforme. É preciso pensar, pois, que em uma sociedade democrática a importância dada aos direitos civis significa a própria subsistência do regime, uma vez que práticas democráticas como o sufrágio com eleições regulares asseguram as instituições na sua legitimidade para proteger os próprios direitos civis. Pode-se, então, de alguma maneira afirmar que dois elementos

\footnotetext{
${ }^{23}$ No período do governo Nixon, Warren Burger foi nomeado como Chief Justice, inaugurando a era Burger na direção da Suprema Corte norte-americana. Embora considerada por muitos constitucionalistas como um período conservador da Corte, na era Burger foram tomadas decisões importantes e de caráter progressista, como no caso Roe v. Wade (1973). Contudo, umas das principais mudanças no posicionamento jurisprudencial da Suprema Corte neste período foi representada pela transição de uma argumentação sobre direitos civis baseada no caso Brown para outra embasada no caso Bolling. No caso Bolling v. Sharpe (1954), a Corte reafirmou a inconstitucionalidade dos regimes de segregação racial nas escolas públicas, contudo, diferentemente de como havia decidido em Brown, o fundamento não estava mais na equal protection clause, mas na garantia da due process clause, prevista na Quinta Emenda à Constituição dos Estado Unidos. O resgate de uma fundamentação embasada na cláusula do devido processo legal contra as políticas segregacionistas, em detrimento da ideia de proteção igualitária, demonstra o caráter mais conservador da Corte no período Burger (GRABER. 2008). Roe v. Wade, 410 U.S. 113 (1973); e Bolling v. Sharpe, 347 U.S. 497 (1954).
} 
são indispensáveis para a segurança do sistema político institucional: direitos civis e procedimentos democráticos; o que são justificados da mesma forma uma vez que trazem um benefício mútuo importante e legitimado por todos os cidadãos.

Within this democratic system of rights, judicial review can be justified rather easily as check on majority rule designed to ensure that civil rights are not infringed. As the above argument implied, there is no guarantee that legislative majorities will always choose the interest of everyone over the interest of a large majority of voters (GRIFFIN, 2002: 299).

A prioridade dada aos direitos civis pode ser o principal objetivo do governo, mas isto não assegura que seja improvável que leis aprovadas violem os direitos individuais. Para solucionar tais problemas é de fundamental importância certos instrumentos ou mecanismos de controle, tais como o judicial review, e isto justifica que tais mecanismos de controle não estão à margem do processo democrático. Nada impede que outros mecanismos existam para sempre corrigir qualquer desvio que o judicial review possa provocar contra os direitos civis que são do interesse de todos, como analisa Griffin:

The argument that there is a harmony between civil rights and democracy thus has subtle implications for the traditional debate over the legitimacy of judicial review. In what I have called a democracy of rights (one that realizes this harmony), judicial review is not brought in to adjust the system toward a goal (the protection of rights) that the system does not naturally achieve on its own. Rather, the point of having a democracy is that it does tend to regularly achieve the successful creation and enforcement of basic civil rights. Judicial review is simply an additional institution that can help achieve this goal (GRIFFIN, 2002: 299).

\section{CONCLUSÃO}

A ideia aqui presente é a de ampliação das possibilidades de deliberação e participação de cidadãos cientes de seus direitos e deveres a partir de interesses comuns. Pode-se apontar que a Suprema Corte pode ser uma das instituições mais preparadas para a deliberação. Mas isto ainda é muito discutido no âmbito acadêmico (GUTMANN \& THOMPSON, 1996).

Os Estados Unidos são, hoje, uma democracia de direitos, com uma lógica constitucional própria com os seus aspectos jurídicos e políticos mesclados dentro de uma ordem institucional de fortes bases. Os poderes políticos são, desde o movimento dos direitos civis, todas as instituições que trabalham em favor da proteção dos direitos individuais, em particular contra a discriminação. Existe, contudo, sempre a possibilidade de conflitos entre esses poderes, pois aqui falamos de democracia e, ao situarmos suas características, aceitamos 0 confronto de opiniões e julgamentos sobre direitos e procedimentos normativos. 
A preocupação existente é que a Suprema Corte possa, em decisões não especificamente pautadas por considerações democráticas, destruir ou afastar direitos civis importantes para a condução da vida em um Estado democrático de direito. Talvez pela prática "freios e contrapesos" é que se encontre sempre "saídas" vitoriosas para a democracia plena.

De qualquer modo, o importante é que existam procedimentos democráticos relativamente confiáveis e bons para identificar políticas que sejam de interesse de todos, criando e efetivando direitos. A ideia de superação dos padrões de julgamento (scrutiny) se baseia apenas na possibilidade dos poderes políticos, como o Congresso, trabalharem com mais eficiência do que a Suprema Corte no que diz respeito à discriminação racial nos EUA. É preciso compreender, contudo, que qualquer assunto que envolva questões de equidade, justiça e discriminação, por exemplo, deve ser combatido por todas as instituições que tenham competência constitucional para assegurar acima de tudo os padrões essenciais da vida democrática. A partir de então, o judicial review torna-se instrumento determinante por integrar a este conjunto de instituições democráticas atuantes na concretização de direitos à Corte Constitucional. Na compreensão da teoria constitucional norteamericana de tais instituições os limites entre direito e política são difusos e esta orientação tem facilitado que sua Suprema Corte reconheça a si mesma no papel democrático de efetivação de direitos e concretize o real valor da justiça constitucional.

\section{REFERÊNCIAS BÁSICAS}

BONAVIDES, Paulo. "Jurisdição Constitucional e Legitimidade: algumas observações sobre o Brasil". Estudos Avançados, vol. 18, n 51, 2004. pp. 127-150.

CANOTILHO, J. J. Gomes. A Constituição Dirigente e a Vinculação do Legislador: contributo para compreensão das normas constitucionais programáticas. Coimbra: Coimbra Editora, 2001.

CARVALHO NETTO, Menelick. "A Hermenêutica Constitucional sob o Paradigma do Estado Democrático de Direito". In: CATTONI, Marcelo (Org.). Jurisdição e Hermenêutica Constitucional. Belo Horizonte: Mandamentos, 2004.

CLAYTON, Cornell. "Law, Politics, and the Rehnquist Court: Structural Influences on Supreme Court Decision Making". In: GILLMAN, Howard; CLAYTON, Cornell (eds.) The Supreme Court in American Politics: New Institutionalist Interpretations. Lawrence, University Press of Kansas, 1999.

COMPARATO, Fábio Konder. "O Poder Judiciário no Regime Democrático". Estudos Avançados, vol. 18, $\mathrm{n}^{\circ}$ 51, 2004. pp. 151-159.

DWORKIN, Ronald. Sovereign Virtue: Theory and Practice of Equality. Cambridge, MA, Harvard University Press, 2000.

. Taking Rights Seriously. Cambridge, MA, Harvard University Press, 1977.

"The Court and the University". University of Cincinnati Law Review, vol. 72, 2003-2004. pp. 883-897.

ELY, John Hart. Democracy and Distrust: a Theory of Judicial Review. 13. ed., Cambridge, MA, Harvard University Press, 2001. 
GARAPON, Antoine. O Juiz e a Democracia: o guardião das promessas. Rio de Janeiro: Revan, 1996.

GARGARELLA, Roberto. "La Dificultad de Defender el Control Judicial de las Leyes". Isonomia, nº 6, abril, 1997.

GRABER, Mark. "The Price of Fame: Brown as Celebrity". Ohio State Law Review, vol. 69, 2008, 939-1015.

GRIFFIN, Stephen. American Constitutionalism: from Theory to Politics. Princeton, Princeton University Press, 1996.

"Judicial Supremacy and Equal Protection in a Democracy of Rights". University of Pennsylvania Journal of Constitutional Law, vol. 4, 2002, 281-313.

GUTMANN, Amy; THOMPSON, Dennis. Democracy and Disagreement. Cambridge, MA, Harvard University Press, 1996.

HABERMAS, Jürgen. Between Facts and Norms: contributions to a discourse Theory of Law and Democracy. Tradução de William Regh. Cambridge, MA, The MIT Press, 1996.

HALL, Kermit. (ed.) The Oxford Companion to the Supreme Court of the United States. Oxford, UK, Oxford University Press, 1998.

KAY, Richard. "American Constitutionalism". In: ALEXANDER, Larry. (ed.). Constitutionalism: Philosophical Foundations. Cambridge, UK, Cambridge University Press, 1999.

KLARMAN, Michael. "Court, Congress and Civil Rights". University of Virginia School of Law-Public Law and Legal Theory Research Paper Series, $\mathrm{n}^{\circ}$ 02-12, 2002.

LASSALLE, Ferdinand. Essência da Constituição. Rio de Janeiro, Líber Júris, 1988.

RAWLS, John. A Theory of Justice. Cambridge, MA, Belknap Press of Harvard University Press, 1971.

. "The Idea of Public Reason Revisited". The University of Chicago Law Review, vol. 64, no 3, 1997, 765-807.

SUSTEIN, Cass. One Case at a Time: Judicial Minimalism on the Supreme Court. Cambridge, MA, Harvard University Press, 1999.

VIEIRA DE ANDRADE, J. C. "Legitimidade da Justiça Constitucional e princípios da maioria". In: Legitimidade e Legitimação da Justiça Constitucional: Colóquio do 10 aniversário do Tribunal Constitucional. Coimbra: Coimbra Editora, 1995. 